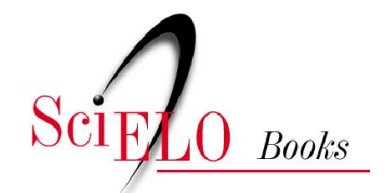

\title{
Prácticas de cuidado al cuerpo articuladas con la alimentación y los trastornos alimentarios trastocando la identidade femenina
}

\author{
María de Lourdes Flores López
}

\section{SciELO Books / SciELO Livros / SciELO Libros}

LÓPEZ, MLF. Prácticas de cuidado al cuerpo articuladas con la alimentación y los trastornos alimentarios trastocando la identidade femenina. In: PRADO, SD., et al. orgs. Estudos socioculturais em alimentação e saúde: saberes em rede. [online]. Rio de Janeiro: EDUERJ, 2016. Sabor metrópole series, vol. 5, pp. 197-214. ISBN: 978-85-7511-456-8. Available from: doi: 10.7476/9788575114568. Also available in ePUB from: http://books.scielo.org/id/37nz2/epub/prado-9788575114568.epub

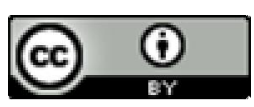

All the contents of this work, except where otherwise noted, is licensed under a Creative Commons Attribution 4.0 International license.

Todo o conteúdo deste trabalho, exceto quando houver ressalva, é publicado sob a licença Creative Commons Atribição $\underline{4.0}$.

Todo el contenido de esta obra, excepto donde se indique lo contrario, está bajo licencia de la licencia $\underline{\text { Creative Commons }}$ $\underline{\text { Reconocimento } 4.0 .}$. 


\section{Prácticas de cuidado al cuerpo articuladas con la alimentación y los trastornos alimentarios trastocando la identidade femenina ${ }^{1}$}

Maria de Lourdes Flores López

\section{Introducción}

Este capítulo presenta una reflexión sobre los costos sociales de algunas formas de cuidado, concretamente al cuerpo y a la dieta, expresados de manera particular por el género femenino, ésta formas de cuidado implican llevar a un nivel reflexivo la reconstrucción de la identidad femenina y su rol social. Se visualiza los costes sociales derivados de ésta búsqueda identitaria articulados por la función nutridora/cuidadora, donde se externaliza el conflicto entre el cuidado al propio cuerpo, y el de otros, mediado no de forma simbólica sino real por el control alimentario que pone de manifiesto y expresa la reproducción de prácticas de cuidado ante está búsqueda y crisis de identidad de lo que significa ser mujer en el mundo moderno. La cuantía se evidencia en un claro efecto que supone una prevalencia elevada de problemas alimentarios particularmente en mujeres, el cuidado al cuerpo y a la alimentación como vías de conflicto.

Se presentan cuatro temáticas reflexivas que abordan una descripción histórica-antropológica y social de cómo se han conformado las diferencias

1 Este trabajo deriva de un estudio más amplio de revisión del estado del arte que se realizó para obtener el grado de doctorado en el Centro de Investigación en Estudios Superiores de Antropología Social en la especialidad de Antropología Médica, Distrito Federal, México. 
de género mediadas en la relación alimentación e imagen corporal, así como las repercusiones de la construcción de estereotipos corporales encaminados a una cultura de la delgadez que plantea otra representación identitaria de la mujer y confluye en un despliegue de consecuencias sociales que pueden verse materializadas en problemáticas alimentarias como son los trastornos alimentarios, en éste último tema se aborda la perspectiva feminista al respecto de las consideraciones del planteamiento como un problema de género.

\section{Diferencias de género y construcción de identidades vinculadas a las relaciones entre alimentación y la imagen corporal}

Existe una estrecha vinculación entre la alimentación y la mujer, así como entre hábitos alimentarios y representaciones del cuerpo, lo cual incorpora implicaciones materiales y simbólicas diferentes entre los géneros (Moore, 1991; Luptón apud Gracia, 2002d, p. 361). Para Gracia, la alimentación, entre otras cosas, constituye una vía para la identificación interpersonal. Alimentar es nutrir, es cuidar, es reproducir, es comunicar. A diferencia de los hombres, las mujeres, en parte por disposición fisiológica y en parte por disposición cultural, son quienes alimentan a las personas durante los primeros meses de vida y quienes, en numerosos contextos, acaban cuidando a los miembros del grupo doméstico durante el resto de su ciclo vital: física y psíquicamente (Narotzky y Subirat apud Gracia, 2002d, p. 361).

Los contenidos culturales que se asocian y se derivan de esta función nutridora/cuidadora son múltiples. Carrasco destaca aquellos que "convierten a las mujeres, dentro de los grupos domésticos, en las receptoras naturales de responsabilidades preventivas, terapéuticas y asistenciales en referencia al grupo para el que cumplen la extensión de esas funciones nutridoras" (2007, p. 81). Esta responsabilidad natural/cultural se puede resumir en la práctica predominantemente femenina de nutrir a los diferentes miembros del grupo, de ofrecerles, a través de las prácticas alimentarias, los alimentos listos para consumirse. ${ }^{2}$ Esto puede interpretarse, en un primer nivel, como la responsabilidad de satisfacer unas necesidades a través de lo culinario que

2 En México, según análisis de Pederzine de la Encuesta de Uso del Tiempo 2002, la cocina es un espacio femenino porque no sólo se destinan un tiempo para cocinar, sino todas las actividades involucradas en la preparación de la comida, planear el menú, comprar ingredientes para la preparación, lavar trastes y limpiar la cocina. Así en promedio las mujeres destinan 
son, en primer lugar, fisiológicas, es decir, de reproducción biológica y de la fuerza de trabajo. Sin embargo, esta tarea comporta "la reproducción y satisfacción de otras relaciones y necesidades sociales y psicológica, tales como reciprocidad, comensalidad, principio de autoridad, control o identidad social y personal que se expresa en cada uno de los contenidos de las actividades que incorpora" (Murcott apud Gracia, 2002d, p. 361). El desarrollo de éstas prácticas diversas permite que el cuidado sea traducido en muchos casos en la representación de identidad del individuo.

Según Gracia y Pederzine (2009), en todas las culturas, la comida es central en el establecimiento de relaciones entre los sexos, en la definición de los géneros y de su sexualidad $\mathrm{y}$, a menudo, las ideas sobre las prácticas alimentarias y el cuerpo reflejan las relaciones de poder y subordinación entre los hombres y las mujeres. En las sociedades occidentales, por lo menos desde hace ocho siglos, las mujeres han usado la comida simbólicamente como una forma de control y poder. ${ }^{3}$ Han sido variados los contextos sociales donde esto ha ocurrido, las mujeres han utilizado el comer compulsivamente, la obesidad, el ayuno o los valores simbólicos de la comida, como vía para expresar y vencer los problemas por alcanzar un lugar significativo en el mundo donde ellas están, por definición, subordinadas (Counihan, 1999). Así, para Gracia, la comida - su restricción o su consumo excesivo - constituyen un elemento para el control personal del peso y, en definitiva, de la imagen corporal, la cual es crucial en las representaciones sociales y en la distinción de los sexos.

Esta distinción se evidencia en las representaciones que se tienen respecto a la corporeidad. Fischler, señala que en el hombre se permite, aún ahora, cierta robustez a diferencia de las mujeres, considerando que los cánones de belleza han sufrido cambios importantes en relación con los de las sociedades tribales y con épocas anteriores de nuestra propia sociedad. La delgadez, la apariencia juvenil es hoy deseada por las mujeres de todas las edades. Aunque el cuerpo femenino tenga, comparativamente, mayor predisposición a la grasa y el masculino al músculo, el cuerpo robusto o gordo en las mujeres no es considerado bello ni sexualmente atractivo actualmente (Contreras, 2002a).

aproximadamente 16 horas en comparación de los hombres quienes participan en 2.9 horas a estas actividades.

3 En México se utiliza en sentido figurado el uso de "dichos" populares que hacen referencia a este poder, por ejemplo: " el amor no entra por los ojos sino por el estómago". 
En los últimos años, se ha construido un nuevo estereotipo de mujer basado en las "super mujeres" que viven entre la carrera profesional y la familia (Fischler, 1995d). Para Contreras, este nuevo estereotipo presenta una mujer emancipada económicamente, inteligente, activa y seductora, pero sin eliminar los papeles tradicionales de responsabilidad doméstica de madre y esposa (presentado en la publicidad sobre todo). La imagen femenina (recurrente en los medios de comunicación) incluye una representación reestructurada del cuerpo físico y una relación de la mujer con su cuerpo distinta a la mantenida anteriormente. El rol de la esposa moderna, sexualmente activa, contrasta fuertemente con el de la mujer puritana del siglo XIX, más preocupada por la maternidad que por su atractivo sexual. Por estas y otras razones, el actual culto a la juventud aparece muy fuertemente entre hombres y mujeres, aunque el atractivo físico es más importante para estas últimas. La preocupación por la salud va acompañada de la preocupación por la línea, es decir, por la belleza (Contreras, 2002a).

Para Fischler, los roles sociales son puestos en tela de juicio. Las imágenes tradicionales de virilidad, feminidad, infancia y adolescencia se confunden. Para este autor, en las sociedades desarrolladas, la fecundidad ya no es tan unánime, monolítica o valorizada, ya no es el núcleo central de la identidad femenina. La reproducción y la fundación de una numerosa descendencia ya no son garantía de una vejez apacible. Los objetivos son más inmediatos e individualistas. El adelgazamiento del modelo corporal coincide con una evolución civilizadora de las costumbres y de la división de los papeles entre los sexos. La mujer se realiza no necesariamente en la reproducción, sino en la producción y la creación. Su función y destino dejan de estar dictados por la familia y el linaje, convirtiéndose en sujeto de su propio destino, entramada cada vez más en la lógica del dominio de sí y, por tanto, del dominio del cuerpo. El parto cambia de sentido, en lugar de ser una función o fin natural se vuelve una experiencia intima, una gratificación, un resultado personal. Para Fischler (1995d), la feminidad, entrando en crisis, ha iniciado un proceso de reconstrucción, donde "la mujer moderna es delgada porque es gorda por sí misma” (p. 355).

Esto permite que se logre la articulación entre claves sociales y claves alimentarias. Se plantea la compatibilidad o ajuste entre la nueva identidad social y las especificaciones biológicas de la mujer. Para Fischler (2002a), existe una fluctuación general, una crisis de los códigos y representaciones alimentarias, que traduce una crisis más general de la cultura y de la civilización, 
y que abre el espacio para una crisis biocultural de la alimentación. Así, los nuevos valores instan a comer menos para estar más bellas, mantener el equilibrio nutricional sin apenas comer, mientras que, por otro lado, se tiene que comprar y preparar comidas deliciosas para los demás. Conflicto de difícil solución, las mujeres transitan entre comidas fáciles, alimentos dietéticos y siguen rodeadas de obligaciones con la comida. De esta forma la alimentación y el cuerpo son vías de conflicto, provocando en muchos casos, que sus exigencias restrictivas sean asimiladas de forma poco coherente y den lugar a conflicto (Contreras, 2000; Gracia, 2006).

\section{Repercusiones de la cultura de la delgadez: reconstrucción de estereotipos corporales}

El cuidado del cuerpo se visualiza como un imperativo en la sociedad actual, las repercusiones o costes sociales por el deseo de la delgadez han sido provistos por la construcción de estereotipos corporales impactando de manera diferencial por género. En el siguiente apartado se muestra la reconstrucción socio-histórica que ha perfilado la cultura de la delgadez, su impacto en los cuidados al cuerpo y sus efectos.

Según algunos autores (Fischler, 1995d, 2002a; Contreras, 2002, 2006; Gracia, 2002d, 2007b), un análisis antropo-socio-histórico de los modelos corporales mostrarían que siempre ha existido una profunda ambivalencia en las representaciones del cuerpo grueso y que la reprobación de la obesidad no es tan reciente como a primera vista pudiera parecer. En el siglo XIX, las referencias a la corpulencia eran positivas; significaban salud, prosperidad, honorabilidad. Sin embargo, existe en "las sociedades arcaicas", una imagen maligna del grueso; el obeso, es también el que come más de lo que equitativamente le corresponde. "Existe un obeso caníbal, comedor de carne fresca, que encarna el mito del ogro a la Gilles de Rais ${ }^{4}$ y que reencarna en parte, en las mitologías modernas, la caricatura del patrón capitalista, este obeso de buena forma, engordado con la sangre y el sudor de las clases trabajadoras" (Fischler, 2002a, p. 378).

Simétricamente, la delgadez o la flaqueza, fue en otros tiempos signo de miseria o de debilitamiento, pero también de pureza ascética e incluso

${ }^{4}$ Gilles de Montmorency-Laval, barón de Rais, llamado Gilles de Rais (o Gilles de Retz) fue un noble y asesino en serie francés del siglo XV. 
de santidad. Sin embargo, prevalecía con mayor contundencia en la mayoría de la población consideraciones sobre lo ventajoso de disponer de una cantidad moderada de grasa acumulada en el cuerpo porque ello mejoraba la resistencia en caso de enfermedad y la delgadez se asociaba con una salud endeble tendiente a la enfermedad, como la tuberculosis (Contreras, 2002a).

Según Gracia (2002d) el culto a la delgadez, sobre todo femenina, parece desprovisto de todo antecedente histórico. Seid (apud Gracia, 2002d) hace un repaso de los modelos ideales de feminidad de las sociedades occidentales, concluye que los cánones de la belleza griega, ejemplificados en Afrodita, estaban más cargados que los nuestros, aunque el ideal femenino parece haber sido más grácil, eran muy diferentes al contemporáneo. Según Gracia, la primera aparición de la delgadez como objetivo explícito de moda se produjo en E.U. durante el período romántico, entre 1830 y 1850, pero apenas duró dos décadas. El imperativo entre mujeres de clase alta, específicamente en la época victoriana y coincidiendo con los ideales femeninos difundidos por la burguesía, según los cuales el cuerpo femenino estaba negado a cualquier tipo de placer o función que no fuera la estrictamente maternal y solamente debía de ser objeto de atenciones si era en relación con la reproducción biológica (Brumberg apud Gracia, 2002d). Sin embargo, a principios del siglo XX el cuerpo femenino va adquiriendo un valor estético, promovido por la alta costura, que pone de moda una silueta más esbelta, "las medidas corporales se convierten en una nueva vía de ansiedad entre las mujeres de las élites, quienes empiezan a tomar conciencia de la necesidad de controlar sus formas corporales para ajustarlas a los cánones de la moda”. (Seid apud Gracia, 2002d, p. 364).

Se impone un canon moderno, que reposa en el imperativo central: delgadez. Según Fischler, coincidiendo con Gracia y Contreras, este canon no parece haber tenido antecedente comparable y se trata literalmente de un ideal de belleza, porque escapa, en efecto, a la realidad; se ha vuelto casi imposible de alcanzar. Biológicamente, "solo el 5\% de mujeres, en una muestra estadística del norte de América, pueden ser tan delgadas como las participantes de un concurso de belleza actual" (Garner et al. apud Fischler, 1995d, p. 341).

En muchas sociedades, a través del tiempo y del espacio, la gordura femenina es o ha sido loada, apreciada, buscada, incluso a veces sistemáticamente cultivada. ${ }^{5}$

5 En ciertos grupos Tuareg, sistemáticamente se engorda a las mujeres antes del matrimonio a través de cebada y engorde regular. 
Fischler hace un recorrido histórico al respecto y señala que las más antiguas representaciones divinas se tratan de imágenes femeninas, las cuales datan del neolítico o del paleolítico superior y, según nuestros criterios actuales, serían en extremo obesas. Las primeras figurillas femeninas en terracota o en piedra cuyo carácter divino está comprobado aparecen en Mureyber, aldea prehistórica del medio Éufrates Sirio, hacia el 8000 a. C. Según Fischler, el consenso científico sostiene que las estatuillas de cuerpos femeninos encontrados son imágenes de un culto de la maternidad y de la fecundidad. Así, "fertilidad y corpulencia, gordura, grasa, se han asociado constante y casi universalmente en las representaciones del cuerpo de la mujer" (Cauvin apud Fischler, 1995d, p. 342).

Según el repaso realizado por Seid quien ha explorado la evolución de la estética del cuerpo femenino y de las coacciones ejercidas sobre él, concluye que los cánones de la belleza griega eran más fuertes al lado de los nuestros. Según Flandrin y Phan, durante el período de la edad media, el ideal femenino parece haber sido más grácil, aunque muy diferente al nuestro (Flandrin y Phan apud Fischler, 1995b). En Estados Unidos, en el período romántico, y más precisamente en los años 1830-1850, cuando parece situarse la primera aparición de la delgadez como objetivo explícito de moda. Pero esta primera moda de la delgadez desaparece hacia 1850. A principios del siglo XX, se instaura definitivamente al modisto Paul Poiret, en 1908, "convertida en la línea neo-imperio, Poiret transforma la silueta femenina atenuando la cintura, alargando las piernas, suprimiendo la ropa interior complicada y otros accesorios constrictores, haciendo aflorar el cuerpo bajo la ropa, sin mediación ni aparato" (Seid apud Fischler, 1995c, p. 344). Desde el siglo XX, sobre todo después de la segunda guerra mundial, es contundente la preferencia por la delgadez. ${ }^{6}$ En 1901, el modelo dominante es el de la "avispa": una cintura muy fina que contrasta con un busto luminoso y unas caderas opulentas.

Otros estudios muestran que las revistas para caballeros (playboy) entre 1960 y 1980 las modelos tienen grandes pechos, la cintura fina y las caderas relativamente anchas. El modelo de "cintura de avispa" se atenúa progresivamente. (Garner et al. apud Fischler, 1995c). El estudio de Seid, de las medidas de la cintura y del peso en las candidatas al concurso de belleza Miss América, muestra datos interesantes: "las Misses en los años 20 median

6 Se evidencia en los estudios americanos, donde se analiza las imágenes de mujeres con traje de baño o ropa interior aparecida en las revistas Vogue y Ladies Home Journal de 1900 a 1981. 
1.73 y pesaban 63.5 kilos, en 1954 median 1.71 y pesaban 54.9 kilos, en 1957, la ganadora media 1.67 y pesaba 54.4 kilos, entre 1980 y 1983 median 1.76 y el pesaban 53 kilos. A partir de 1979, la ganadora pesa siempre menos que las otras competidoras" (Seid apud Fischler, 1995c, p. 344).

A través de los siglos, según Aimez, la historia de la imagen femenina del cuerpo construida por las culturas occidentales parece caracterizarse por la plasticidad. Se trata de un cuerpo como cera maleable, a veces hinchado y estirado, forzado, moldeado y erguido, completamente disimulado o parcialmente exhibido (Aimez apud Fischler, 1995b). Así observamos, al menos a través de este siglo, las modificaciones al ideal del cuerpo femenino han afectado no sólo al peso y al grosos del cuerpo global, sino también la estatura. Según Fischler, lo que caracteriza el período más reciente es, la musculatura y el vigor del cuerpo; hoy el cuerpo femenino moderno debe ser - y en esto no hay precedente- todo músculo, toda firmeza y sin blandura. Todo rasgo de adiposidad está proscrito.

En el estado actual que aplica este recorrido, que nos muestra Fischler, parece que opera un doble movimiento en el vestido y el cuerpo de la mujer occidental: del vestido al cuerpo y de la madurez a la juventud. Para este autor, "detrás de este doble fenómeno, así como de la lipofobia, hay una profunda y radical transformación del papel y de la imagen de la mujer" (Fischler, 1995c, p. 345).

Para otros autores, ciertamente, los comportamientos y los cuidados corporales han sufrido cambios en relación con sociedades tribales y con épocas anteriores de nuestra sociedad, representan una práctica disciplinaria del gobierno del cuerpo asociada a la racionalización de la vida cotidiana (Tuner y Conevey apud Gracia, 2002d). Para Contreras (2002) y Fischler (1995b), la asociación entre gordura, salud y prosperidad empezó a desaparecer a principios del siglo $\mathrm{XX}$, como consecuencia de la acción de los médicos y de las compañías de seguros. Ambos colectivos proporcionan un tipo de "cuerpo ideal" bastante más delgado que el estereotipo anterior. Según estos autores, es a partir de 1900 cuando aparecen los actuarios médicos con estándares de peso y salud y se sugiere que el sobrepeso es un riesgo para la salud. Coincidiendo con la información suministrada por las compañías de seguros que, ya desde mediados del siglo XIX, usaban el peso corporal como indicador de riesgo. Es así como las tablas utilizadas por las compañías de seguros resultaron decisivas en el establecimiento de los primeros promedios de peso ideal. 
Según Contreras, en los últimos 40 años se han consolidado una serie de cambios en relación con el ideal del cuerpo, tanto masculino como femenino, de tal manera que el deseo de salud, de longevidad, de juventud y atractivo sexual son una poderosa motivación contra la obesidad. Así, las ideas sobre el cuerpo y la salud tienen una influencia muy directa y muy importante sobre la cultura alimentaria y los comportamientos alimentarios que se consideran adecuados. El valor moral atribuido a la delgadez y al régimen se justifica generalmente en nombre de la salud. Estética Física y rasgos de personalidad asociados con el físico, se hacen contundentes. La delgadez es presentada como atractiva, también asociada con el éxito, el poder y otros atributos altamente valorados. La gordura es considerada fisicamente y moralmente insana, obscena, propia de perezosos, de glotones o de pobres. Las evaluaciones positivas y negativas del físico proyectan, por inferencia, "a los patrones típicos de conducta correlacionados con atributos morales: autocontrol y autoindulgencia” (Contreras, 2002a, pp. 257-86)

\section{Los costos sociales: la búsqueda por la delgadez corporal, la situación en México}

En México, a pesar de las diferencias sociales, se observa la interiorización de este estereotipo, esta preocupación está presente en todos los sectores de la población, aunque no se manifiesta del mismo modo. Bertran (2010) analiza el panorama de la alimentación vinculado con las representaciones del cuerpo en la ciudad de México desde una perspectiva antropológica y señala: "en los sectores bajos la preocupación de la imagen es importante como una cuestión de salud y también como un asunto de vanidad" (p. 387). En los sectores medios y altos, la imagen y la salud son claramente percibidas como símbolos de bienestar, como un ideal social. Un cuerpo bello es sano, refleja bienestar, no sólo por lo que se siente sino cómo se ve. La delgadez es el ideal a conseguir lo que se obtiene fundamentalmente por la comida saludable, baja en grasa, haciendo ejercicio, tomando mucha agua, sometiéndose a tratamientos corporales incluyendo las cirugías estéticas (Bertran y Arrollo, 2006). Para estos autores, la corporalidad es un agente social que señala las posibilidades económicas, culturales y de tiempo. Esta ideación sobre la delgadez también ha sido explorada por otros autores en zonas rurales del país (Pérez Gil, 2007a, 2008, 2010; Tinat, 2008a), observando la asimilación del estereotipo de corporal actual, expresada por el anhelo por la delgadez, el ser delgada es sinónimo de belleza, el malestar frente 
a la comida y el cuerpo, la preocupación por la apariencia y la imagen corporal y se muestra un claro rechazo a la obesidad.

La población mexicana enfrenta una paradoja alimentaria muy relevante. La delgadez es el ideal corporal social, sin embargo el sobrepeso y la obesidad aumentan "la gente se sabe gorda y se sueña delgada" (Contreras, 2002a, p. 282). En nuestro país, el $70 \%$ de la población tiene sobrepeso. Se evidencian diferencias ante este panorama, según Bertran y Pérez-Gil, al mismo tiempo que se busca la delgadez y la salud, el bienestar está también se promueve el placer y el gusto, el consumo de alimentos industriales que además de ser baratos dan prestigio, cumplen los ideales de modernidad (Oseguera, 1996). El hedonismo, como nunca antes, la cocina, la gastronomía, la búsqueda de alimentos nuevos, de sabores nuevos está presente como parte de la vida diaria, en todos los niveles. Según Bertran, en los sectores altos, este hedonismo se expresa en las nuevas propuestas gastronómicas de la industria restaurantera que proponen más que una salida a comer, una experiencia sensorial. En los sectores bajos el acceso reciente al Fast Food Americano, permiten acceder a una nueva y moderna forma de vida, que conviene sobre todo a la mujer incorporada al campo laboral facilitando su quehacer en el cuidado y provisión de alimentos. Se conviven el placer y el hedonismo, con el control del consumo para guardar la línea y la salud (Oseguera, 1996; Bertran, 2010; Ortiz, 2006; Peña, 2000a). La comida se presenta como un conflicto que confronta la propia identidad en la búsqueda de cuidar el cuerpo para poder ser y el cuidado de los otros.

La alimentación como una función específica de la mujer dado por aspectos fisiológicos y culturales nos remite al cuidado de los otros en diversos contextos, confluyen en un momento histórico donde las representaciones del cuerpo, asociadas a esta función reproductora y cuidadora, es decir al rol social que por varios lustros a sustentado el papel social de la mujer, se colocan en tela de juicio. Evidenciamos un enclave entre el rol social de la mujer y la relación con la alimentación, como una función de género, que entra en conflicto dado las nuevas representaciones de la mujer actual. Este enclave nos permite introducir una vía de expresión de dicho conflicto, los trastornos alimentarios que se presentan como un problema que afecta en mayor proporción a las mujeres ${ }^{7}$ pone de manifiesto las nuevas tonalidades

7 En los años 90 en México se reportan casos sobre todo asociado a la anorexia y bulimia. Los estudios empezaron a describirlas y analizarlas mostrado la interiorización de ideales en los estereotipos corporales, de la lipofobia y del régimen dietético, sobre todo en mujeres adultas 
que detona el cuidado hacia los otros y así sí mismo en un hecho cotidiano como la alimentación y su vinculación con la imagen corporal.

\section{Los transtornos alimentarios desde la perspectiva médica y el enfoque feminista}

Desde la Biomedicina, y según los datos epidemiológicos, son las mujeres quienes tienen más riesgo que los hombres de padecer trastornos del comportamiento alimentario (TCA). Gracia señala que esta visión se da porque la Biomedicina considera que las mujeres son más sensibles a las presiones sociales sobre las formas corporales y más vulnerables a las alteraciones nutricionales. Para esta autora los trastornos se presentan desde la Biomedicina como enfermedades mentales cuyo trasfondo psicológico y biológico de los síntomas no se puede desligar del contexto en el han sido elaborados. Así, señala que la asociación que se hace sobre trastornos y mujeres jóvenes, se explica por una supuesta mayor dependencia personal y emocional, por una menor autoestima "relativa a la incapacidad para comunicarse o por su inclinación a acatar más estrictamente o menos críticamente los dictámenes del marketing y la moda" (Gracia y Comelles, 2007, p. 35). Sin embargo, fuera de la clínica, los autores consideran que se evidencian sus contradicciones y se "proyectan de modo más transparente metáforas y valores - buenos y malossobre ciertas formas de comportarse con la comida y con el cuerpo: el cuerpo como prisión, la vida como un menú, el ayuno como autocastigo, la gordura como epidemia” (Gracia, 2007e, p. 29).

Según Gracia, el feminismo señala la imagen social de la mujer como causa principal de los problemas del comportamiento alimentario, considerando que la obligación social que recae sobre la mujer de ser artificialmente delgada, los medios de comunicación contribuyendo a la fetichización y a la cosificación de un cuerpo femenino anormalmente esbelto, o el apremio para que las mujeres se esfuercen en ser buenas esposas, madres, trabajadores y atractivas amantes (super-mujeres), constituyen algunas de las razones originarias que envuelven a estos problemas. Las demandas feministas

y adolescentes en diferentes contextos no sólo en centros urbanos y estratos altos de las principales ciudades, como era caracterizado en los países desarrollados (Lora-Cortéz, 2006; Álvarez, 2007; Casillas-Estrella, 2007). 
han puesto atención en los factores culturales que contribuyen a los trastornos del comportamiento alimentario (Gracia, 2002f).

Chernin (1985), habla de la "tiranía de la delgadez", la cual limita el desarrollo de la mujer desde todos los puntos de vista: social, personal y físico. Chermin equipara metafóricamente los estándares de belleza más delgada con las presiones a que están sometidas las mujeres de "hacerse más pequeñas, más estrechas, más ligeras, con menos gravedad, de reducirse a sí mismas" (Chernin apud Gracia, 2002f, p. 371). Las mujeres, a diferencia de los hombres, parecen tener la obligación de avergonzarse de sus cuerpos y, en consecuencia, proceder a modificarlo a través de cualquier procedimiento. Chernin, apunta que las mujeres se ven forzadas a imitar a los hombres para acceder al poder, adoptando el semblante masculino en los centro de trabajo. Así, "la presente epidemia de los trastornos alimentarios debe ser entendida como una profunda crisis de desarrollo en una generación de mujeres todavía profundamente confundidas, después de dos décadas la lucha por la liberación femenina, acerca de lo que significa ser mujer en el mundo moderno" (Chernin, 1985, p. 17).

Según Chernin, los problemas alimentarios que aparecen, sobre todo en la adolescencia, muestran conflictos graves de identidad femenina en edades en que las mujeres son invitadas a replicar todavía la imagen burguesa sobre aquello que ha de ser una mujer: a reproducir una ideas que enfatizan el cuerpo físico, la imagen externa más que su cerebro, mientras que experimentan la transformación sexual de su cuerpo. Estos conflictos con la comida son manifestaciones de problemas de identidad que esconden una profunda lucha de separación entre madre/hija adolescente, especialmente cuando se espera que la hija supere a la madre en la inserción social. Para esta autora, dichos cambios obedecen a que la situación sociocultural de las mujeres se transforma sobre todo desde la década de los sesenta y las actitudes así como las tareas productivas cambian, son productivas en tanto son remuneradas. La formación académica también comienza a valorarse más que las responsabilidades reproductivas. De hecho, la hija ha de "sentirse sujeto femenino, fisicamente, pero también sujeto social, dando un rendimiento intelectual" (Chermin apud Gracia, 2002f, p. 372)

Por su parte Bordo (1993) amplia las explicaciones reducidas al vínculo madre/hija, explora minuciosamente las complejas intersecciones y las cristalizaciones de la cultura que están presentes en los fenómenos de 
los trastornos alimentarios. Tales elementos incluyen las actitudes culturales generales, la valoración de la delgadez en nuestra cultura, el rol de la cultura de consumo, las representaciones culturales de la mujer, de la abstinencia y de la comida, la medicalización de los desórdenes alimentarios y de otros desórdenes femeninos (histeria, desórdenes de ansiedad, obsesión, etc.). Su análisis plantea un proceso dialéctico, identificando las cristalizaciones e interacciones mutuas, en contraste con los modelos causales dualísticos que aportan las perspectivas médicas (normal/desviado). La crítica más fuerte que hace al modelo médico reside en su argumento de que el peso de las mujeres y las conductas dietéticas voluntarias "normales" permanecen en el mismo continuum que los desórdenes alimentarios femeninos:

la mayoría de las mujeres en nuestra cultura, entonces, están "desordenadas" a consecuencia de valorar, autorizar y confrontar a sus propios cuerpos; los desordenes alimentarios, lejos de ser estrafalarios y anormales, son completamente continuos con el elemento dominante de la experiencia de ser mujer en esta cultura (pp. 23-42).

Para Bordo, es insensato sugerir que la intensificación de la preocupación por las formas corporales y las dietas, comúnmente en la población no clínica de adolescentes, puede ser la indicación de una expresión parcial, o ligera, de la enfermedad. Según Bordo, el modelo médico de los trastornos alimentarios como enfermedad/dolencia es tan firme que le procuraría medicalizar a la mayoría de las mujeres adolescentes.

Bordo y Chernin siempre han acentuado en sus trabajos la intersección de la cultura con la familia, el desarrollo económico e histórico y las construcciones psicológicas del género, constituyendo estas variables el eje del modelo cultural/feminista predominante que ha dado hipótesis de trabajo realmente sugerentes. Bordo señala que esta corriente es la única que "ha amenazado profundamente el modelo médico o, al menos se ha enfrentado a él, al ofrecer alternativas teóricas y metodológicas para el abordaje de estos problemas" (apud Gracia, p. 373).

Los trabajos de Chernin y Orbach desafían la designación de Trastornos alimentarios como psicopatologías, enfatizando los aspectos aprendidos e incorporados de estas conductas y rescatando los roles de la cultura y del género como factores primarios en el inicio de los trastornos alimentarios, antes que 
como mantenedores o contributivos, a la vez que refuerzan la reasignación de las causas disfuncionales individuales a los factores sociales. La crítica, también, incluyen una dimensión más amplia e, incluso, contextualizan los trastornos conjugando los roles que desempeñan las preocupaciones médicas y de salud mental, los organismos corporativos, la industria de la belleza y la moda y otros intereses creados.

En cuanto a las causas que apuntan que las mujeres son las más afectadas por los trastornos alimentarios, "las mujeres sufren trastornos del comportamiento alimentario porque hay algo erróneo o confuso en ellas: están "loca" - o al menos son mentalmente anormales - o tienen deficiencias bioquímicas” (Gracia, 2002g, p. 374). La posición del modelo feminista/ cultural considera que, si bien, el entorno cultural ayuda al incremento de las psicopatologías, no se puede considerar la causa. Para Bordo, la respuesta a esta crítica es clara: "No todos estamos expuestos de igual manera a este entorno cultural, sino que dicha exposición se ve condicionada por factores como la etnia, la clase social, la edad, la educación, la religión, la orientación sexual, la familia o la estructura genética, de tal forma que se producen interacciones personales con las imágenes culturales y, en consecuencia, interpretaciones y respuestas diversas" (Bordo, 1993, p. 139).

Los estudios de Zafra (2009, 2008a, 2007b) nos muestran un ejemplo de lo anterior. La autora hace énfasis en los aspectos aprendidos e incorporados en la afectación de la problemática alimentaria en mayor proporción en mujeres que en hombres así como la inoperatividad de los criterios o categorías que presumen un diagnóstico de "trastorno" desde la Biomedicina. Zafra analiza y contrasta los discursos de hombres y mujeres adolescentes diagnosticados con algún "Trastorno Alimentario" con los de otros pares sin un diagnóstico médico, mostrando como la socialización alimentaria puede dar cuenta de la causalidad y sintomatología.

Zafra muestra que son los procesos de socialización con la cultura los que inciden en la conformación e interiorización de prácticas y actitudes hacia la comida y la alimentación diferentes y desiguales en hombres y mujeres. Su análisis muestra como se expresa una mayor o menor "susceptibilidad" de un género u otro a padecer un determinado problema alimentario, encontrando similitudes en el discurso entre los diagnosticados y no diagnosticados en relación con los criterios diagnósticos propuestos por la medicina que caracterizan los Trastornos Alimentarios como la "distorsión de 
la imagen corporal", la "insatisfacción corporal y el rechazo a mantenerse en el peso adecuado", el "miedo a engordar", y los "atracones y comportamientos compensatorios", no sólo aparecen en las personas diagnosticadas de TCA, sino también en la mayoría (más del 50\% de los casos) de los/as adolescentes no diagnosticados/as entrevistados/as. También hace evidente las diferencias de género al respecto. La insatisfacción corporal, el miedo a engordar, la distorsión de la imagen, los atracones y los comportamientos compensatorios están más presentes en las mujeres que en los hombres.

Zafra observa y evidencia que el significado que durante el proceso de socialización va adquiriendo el comer y/o el no-comer para los hombres y las mujeres es distinto y desigual en tanto que también lo es su contexto de socialización, es decir, la manera como interaccionan en y con el medio familiar, los/as amigas/os, la escuela y los medios de comunicación. Para Zafra, mientras que a las mujeres se les enseña y aprenden más a controlar su cuerpo y a manifestar sus sentimientos a través de la alimentación, a los hombres se les enseña y aprenden más a controlar su cuerpo y expresarse a través del ejercicio físico y el deporte. Así, la autora muestra cómo estos factores del proceso de socialización condicionan el aprendizaje diferente y desigual en función del género con respecto a la alimentación.

Los argumentos acerca de las causas y el abordaje de esta problemática alimentaria van y vienen, oscilando en la actualidad entre las corrientes que ponen su énfasis en el tratamiento individual de las personas, particularmente mujeres, que presentan estas conductas/desviaciones, aun reconociendo la contribución de las presiones del entorno, y en las que fijan su interés en los resultados de la encrucijada cultura/persona, reclamando una mayor intervención sobre el plano social como origen primario de estas conductas, que presentan, por otro lado, una continuidad subyacente a los elementos normales de la cultura (May apud Gracia, 2007b). Sin embargo, como menciona Gracia: "lo que entra en cuestión es el éxito de cada una de las perspectivas que intentan dilucidar el por qué de las conductas alimentarias consideradas trastornos". Se plantea cuánto éxito ha tendido el modelo feminista/cultural frente a las pretensiones médicas basadas en las disfunciones individuales, desviación y estigma que, que a su vez están siendo legitimadas por los medios, los organismos corporativos, las industrias de la cosmética o la moda como la verdad objetiva, permitiendo posicionar la problemática desde una perspectiva reduccionista, menos enfática y crítica 
que cuestione las causas del conflicto derivados de un entramado complejo en la reconstrucción y reproducción identitaria de la mujer.

\section{Conclusiones}

Describimos, analizamos y reflexionamos a través de una revisión temática socio-antropológica un aspecto del cuidado al cuerpo y la dieta. Utilizamos como vía de aproximación y objeto de estudio la relación establecida entre la función nutridora/cuidadora que ha comportado de manera genérica por varios lustro y denota el rol social de la mujer. Éste se coloca en la punta de conflicto dado las transformaciones del papel que juega la mujer en esta cultura avasallante por el consumo, por el valor moral atribuido a la delgadez, sinónimo de éxito, poder y otros atributos altamente valorados. Dimos cuenta de la construcción de estereotipos corporales que favorecen y fomentan estos ideales, así como del conflicto que se genera entre la búsqueda de éstos y su relación con la alimentación, donde la vertiente principal de cuidado a los otros ha virado al cuidado propio, remitiendo a la necesidad de identificación y realización a partir de mirarse a sí mismo. Los costos sociales y la crisis de identidad del papel fundamental de la mujer entran en juego evidenciado en las problemáticas alimentarias, los trastornos de la alimentación se presentan como situaciones que competen a las mujeres. A propósito hemos mostramos la perspectiva médica y feminista al respecto, considerando que la visión médica reduce la situación colocando el problema en una categoría de enfermedad o dolencia y limita en enfoque critico que vislumbre el proceso continuo que implica, como diría Bordo, vivir la experiencia de ser mujer en esta cultura.

\section{Referencias}

BERTRAN, V. "Acercamiento antropológico de la alimentación y salud en México". Physis Revista de Saúde Coletiva, Rio de Janeiro, v. 20, n. 2, 2010, pp. 387-411.

BORDO, S. Unbearable weight: feminism, western culture, and the body. Califórnia: University of California Press, 1993, pp. 23-42.

CARRASCO, N. "Desarrollo de la antropología de la Alimentación, en América Latina: hacia el estudio de problemas alimentarios contemporáneos". Estudios Sociales, v. 16, n. 30, 2007, pp. 81-101. 
CONTRERAS, J. Alimentación y cultura: necesidades, gustos y costumbre. Barcelona: Editorial Alfaomega/Universidade de Barcelona, 2002a.

- "La obesidad: una perspectiva sociocultural". Formación Continúa en Nutrición y Obesidad, Espanha, v. 5, n. 6, 2002b, pp. 275-86.

— e GRACIA, M. "Epilogo”. Alimentación y cultura: perspectivas antropológicas. Espanha: Editorial Ariel, 2005.

COUNIHAN, C. The anthropology of food and body: gender, meaning, and power. Nova Iorque: Routledge, 1999.

FISCHLER, C. El (h)omnivoro: el gusto, la cocina y el cuerpo. Barcelona: Anagrama, 1995a. (Colección Argumentos)

__. "La sociedad lipófoba”. In __. El (h)omnivoro: el gusto, la cocina y el cuerpo. Barcelona: Anagrama, 1995b, pp. 297-321. (Colección Argumentos)

__. "El cuerpo femenino: de Calipige a Tanagra". In __. El (h)omnivoro. El gusto, la cocina y el cuerpo. Barcelona: Anagrama, 1995c, pp. 341-56. (Colección Argumentos)

—_. "Gastro-nomía y gastro-anomía: sabiduría del cuerpo y crisis biocultural de la alimentación contemporánea”. In CONTRERAS, Jesús (org.). Alimentación y cultura: necesidades, gustos y costumbres. Espanha: Editorial Alfaomega, 2002, pp. 357-80.

GRACIA, M. Paradojas de la alimentación contemporánea. Espanha: Icaira, 1996, pp.193-201. "El clima social: presiones hacia la delgadez". In . Somos lo que comemos: estudios de alimentación y cultura en España. Espanha: Ariel, 2002a, pp. 364-71.

- Somos lo que comemos: estudios de la alimentación y cultura en España. Espanha: Ed. Ariel, 2002b, pp. 9-12.

__ "La especificidad femenina de los trastornos alimentarios ¿por qué las mujeres?". In . Somos lo que comemos: estudios de alimentación y cultura en España. Espanha: Ed. Ariel, 2002c, pp. 361-71.

"El modelo feminista y los trastornos alimentarios" In . Somos lo que comemos: estudios de alimentación y cultura en España. Espanha: Ed. Ariel, 2002d, pp. 371-4.

— “Aprender a comer?: el (re)establecimiento de la normalidad dietética en el caso de los trastornos del comportamiento alimentario”. In GALARZA, Mari e PALLARÉS, Joan (orgs.). La salud en una sociedad multicultural: desigualdad, mercantilización y medicalización. Congreso de Antropología, Sevilha, 2005.

"Cultura, práctica médica y prácticas alimentarias". In . No comerás: narrativas sobre comida, cuerpo y género en el nuevo milenio. Barcelona: Icaria, 2007, pp. 36-8.

—_ "La obesidad como problema social: la ideación sobre su carácter crónico, plurifactorial y epidémico”. In ROMANI, Oriol et al. (orgs.). Antropología de la medicina, metodología e interdisciplinariedad de las teorías a las prácticas académica y profesionales. XI Congreso de Antropología de la FAAEE. Espanha: Donastia, 2008, pp. 63-78.

—. "Relaciones entre biología, cultura e historia en el abordaje de los trastornos alimentarios". In XAVIER MEDINA et al. (orgs.). Estudios del hombre, antropología de la alimentación, food, imaginaries and cultural frontiers: essays in honour of Helen Macbeth. Guadalajara: CUCSH/Universidade de Guadalajara, 2009, n. 24, pp.76-88.

_ e COMELLES, J. "Comer o no comer, ésa es la cuestión”. In __. No comerás: narrativas sobre comida, cuerpo y género en el nuevo milenio. Espanha: Icaria, 2007, pp. 28-36. 
OSEGUERA, D. "El Fast-food y el apresuramiento alimentario en México”. Estudios sobre las Culturas Contemporáneas, v. 11, n. 3, 1996, pp. 109-35.

PEDERZINE-VILLAREAL, C. "La cocina ¿destino o privilegio femenino?”. In MENDOZA ÁLVAREZ, Carlos e MONTOYA, Ángel Francisco (orgs.). Pan, hambre y trascendencia: diálogo interdisciplinario sobre la construcción simbólica del comer. México: Universidad Iberoamericana, 2009.

PÉREZ-GIL, S. "Prácticas alimentarias de mujeres rurales: ¿̨una nueva percepción del cuerpo?”. Salud Pública de México, v. 49, 2007, pp.52-62.

__. "Imagen corporal en mujeres rurales de la Sierra Juárez y la costa de Oaxaca: una aproximación nutrio-antropológica”. Estudios Sociales, México, v. 16, n. 32, 2008, pp. 81-111.

— e ROMERO, G. "Imagen corporal en mujeres de tres zonas rurales de México: percepción y deseo". Salud Pública de México, v. 52, 2010, pp.111-18.

TINAT, K. “¿Existen la 'anorexia’ y la 'bulimia’ en el medio rural? Nuevas representaciones y prácticas alimentarias y corporales entre los jóvenes de Patamban, Michoacán”, Estudios Sociológicos, v. 26, n. 3, 2008a, pp. 647-67.

—_ "De jóvenes, cuerpos y alimentos: la reconstrucción de un itinerario de investigación". Estudios Sociológicos, v. 26, n. 1, 2008b, pp. 179-96.

ZAFRA, E. Aprender a comer: proceso de socialización y trastorno del comportamiento alimentario (tese). Universidade de Barcelona, 2007. Disponível em: www.tdx.cat/bitstream/10803/53633/1/EZAFRA_TESIS.pdf. Acesso: 29 jun. 2013.

- "Los trastornos del comportamiento alimentario como estares alimentarios entre el placer (bienestar) y el conflicto (malestar)". In ROMANI, Oriol et al. (orgs.). Congreso de Antropología de la FAAEE: Antropología de la medicina, metodologías e interdisciplinariedad: de las teorías a las prácticas académicas y profesionales. Espanha, 2008, pp. 233-47.

- "Los criterios de diagnóstico de los trastornos del comportamiento alimentario desde la perspectiva antropológica”. Memorias del Congreso Español de Sociología de la Alimentación. Espanha: Gijón, 2009. 